\title{
SMALLHOLDER FARMERS' PERCEPTIONS OF AGRICULTURAL EXTENSION IN ADOPTION OF NEW TECHNOLOGIES IN KAKAMEGA COUNTY, KENYA
}

\author{
aNewton M. Nyairo*, bLinda J. Pfeiffer, bMark Russell \\ a Department of Agriculture and Natural Resources, Langston University, Langston, United States. \\ ${ }^{b}$ Department of Agricultural Sciences Education and Communication, Purdue University, West Lafayette, United States.
}

\section{ART ICLE INFO}

\section{Article History}

Received: January 18, 2020

Revised: March 12, 2020

Accepted: April 27, 2020

\section{Keywords}

Technology adoption

Agricultural extension

Agricultural innovations

Food security

Logistic regression

Smallholder farms
A B S T RAC T

This exploratory study assesses factors that harness agricultural technology adoption among smallholder farmers in Kakamega County, Kenya by evaluating the key variables that influence sustainable adoption of agricultural innovations in the area. A survey was randomly administered in June and July 2018 among smallholder farming households in seven sub-counties ( $\mathrm{N}=78)$ of Kakamega County. A logistic regression model, capturing factors presumed to influence the adoption of agricultural innovations, was estimated. Results suggest that even in smallholder farms, the farm size is important in adoption of innovations. Results also indicate limited or no farmer interaction (55\%) with extension services. Farmers reported application of fertilizer and use of push-pull technology as less important in maintaining soil health. The regression model findings suggest that variables typically presumed to influence adoption in the literature are insignificant in this case study. The statistical significance of the farm size variable implies that agricultural extension messages can be tailored to a variety of farmer audiences for suitable adoption based on farm size. The diffusion of innovation theory remains a valid and relevant framework in studying adoption. This study reiterates the critical role that farmers or their environment play in the adoption process.

Corresponding Author: Newton M. Nyairo

Email: newton.nyairo@langston.edu

(C) The Author(s) 2021.

\section{INTRODUCTION}

Kakamega County is located in the former Western Province of Kenya and covers a land area of 3,050.3 km2. Administratively, the county has twelve (12) subcounties and 398,709 households. According to the Agricultural Sector Development Support Programme (ASDSP) of Kenya, the economy of Kakamega County is driven by agriculture, mainly smallholder agriculture. Agriculture is the leading source of income and food security in the region and contributes significantly to the economy of the county. Achieving Agricultural productivity, through expanded access to appropriate agricultural technology, is important in improving the conditions of the poor, the majority of whom rely on agriculture for their livelihoods. To ensure sustained economic growth in the county, supporting the agricultural productivity of smallholder farmers is essential.

The central objective of this study is to explore the factors that contribute to the adoption of new agricultural practices by smallholder farmers in Kakamega County, western Kenya. Understanding how farmers make decisions that result in the adoption of yield-increasing agricultural practices is important in the design of effective public and private agricultural extension services. The latter service providers are 
privately funded through non-governmental organizations (NGOs), as well as other private service providers. Extension service delivery is, however, complicated by the reality that farming systems in Kakamega County are complex, varying with diverse physical, biological, and socio-economic conditions (Ochenje et al., 2016). Kakamega varies in its biophysical characteristics - different soil textures and considerable crop biodiversity (Ochenje et al., 2016; GOK, 2014). In this region, mixed agriculture is widely practiced, with farmers raising livestock and growing a variety of crops year-round. Notwithstanding the region's overall agricultural potential, aggregate agricultural output remains sub-optimal with households receiving meagre agricultural incomes (Adolwa et al., 2017). As a consequence, many households perpetually grapple with low agricultural returns, poverty, and food insecurity (Davis, 2008; Mutua et al., 2010).

In aggregate, the promotion of agricultural technologies in this region cannot be described as successful (Tittonell et al., 2005), and this is reflected in the poor or declining crop yields in areas where technology adoption is low (Aura, 2016). The decline persists despite the intervention of both private and public extension agents working with farmers (Mwaura et al., 2021; Odulaja and Kiros, 1996). Extension education and training programs are intended to provide skills and resources to improve farming practices, and to transmit knowledge that overcomes farmer agricultural challenges and improve agricultural production efficiency.

Previous research in this region has focused on various aspects of agricultural technology adoption including joint adoption of common inputs, such as fertilizer (Ogada et al., 2014) and the application of best management practices (Tittonell et al., 2005). However, these studies emphasized technology adoption without evaluating the direct role of farm and farmer characteristics in their promotion of and impediment to new agricultural practices. Therefore, the research continues to reflect a gap in understanding the role that both farm and farmer characteristic play in the adoption of yield-enhancing practices.

Given the importance of agriculture in economic growth, a more comprehensive review of the full range of factors responsible for the adoption of agricultural technologies is essential. Successful improvement of the quality of livelihoods of smallholder farmers in developing countries cannot be sustained until the factors inhibiting growth of agricultural productivity are well understood (Odulaja and Kiros, 1996). This exploratory study was conducted to identify key factors that influence technology adoption among smallholder farms in western Kenya. The first research question explored local farmers' views of extension and the agricultural techniques it encourages among local farmers. The second research question addressed the potential farm and farmer characteristics that influence technology adoption among smallholder farmers.

The objective of this exploratory study was to provide an overview of the factors that influence the adoption of agricultural technologies among smallholder farmers in Kakamega County, Kenya. This objective is investigated by answering the stated research questions. The diffusion of agricultural innovations remains important in contributing to the enhancement of agricultural productivity among smallholder farmers, an outcome that is likely to improve their livelihoods and to reduce food insecurity. The study focuses on fertilizer, an input that is used by farmers in many parts of Kenya and in other developing countries.

This paper is organized into five sections. The first section introduces background information on agriculture in Kakamega County, Kenya, and outlines smallholder agricultural practices in the region. Section two defines the diffusion of innovation theory and its application in this region. The history and evolution of agricultural extension in Kenya is reviewed in section three. Section four outlines the need for new models of extension in developing countries. The section concludes with an analysis of how the three primary extension models are commonly used to deliver agricultural services in developing countries and highlights the variability of extension that farmers access.

\section{Background of study area}

In Kakamega county, rain-fed agriculture is a common source of water that farmers rely upon for growing crops and raising livestock. The application of irrigation water in agriculture is not commonly used in many farmlands. In this region, precipitation varies throughout the year with October through March receiving low amounts of rain and April through September receiving the most rain during the year. The incidence of rainfall remains a critical climatic factor that influences crop performance. The areas that receive insufficient rainfall experience 
poor crop performance compared to those that do (AliOlub et al., 2011). Overall, the region enjoys a tropical climate, favorable for raising livestock and growing a variety of crops including maize, beans, cassava, bananas, and potatoes.

Agricultural production in the county is mainly for subsistence production, mostly meeting the households needs and local requirements, with a limited amount for commercial purposes (Ali-Olub et al., 2011). Farming systems and socio-economic conditions are largely homogeneous across the region with considerable variability in farmer implementation of best management practices (Tittonell et al., 2005). Research on the diversity of soil fertility management in western Kenya suggests that farmers manage their fields according to their perception of land quality (Tittonell $e t$ al., 2005). The variability and intensity of soil management practices are done according to the soil fertility gradients. In soil fertility management regimes, farmers manage crop production using organic and mineral nutrient resources. Application of manure or chemical fertilizer occurs in fields near their homesteads rather than fields located further away. This inconsistent fertilization of the fields is argued to contribute to overall declining crop yields in some part of the region, and also making soil amendment practices an interesting area for further research on the adoption of new technologies in soil productivity (Tittonell et al., 2005).

Typically, farmers in Kakamega County practice smallscale agriculture and own farm sizes less than 10 acres on average. During the 1990s, sugar production, which had been the dominant crop, faced management challenges that contributed to the decline in the performance of the sugar industry. This decline led farmers to opt for growing other crops, such as maize and beans (GOK, 2014). Most of these households, particularly those located around urban areas, derive additional earnings from small business activities, such as operating consumable shops or selling clothes in flea markets. The additional earnings supplement their farm incomes (GOK, 2014).

\section{Theoretical Approach}

The diffusion of innovations paradigm, introduced in the 1950s by agricultural sociologists in the Midwestern United States, sought to explain the communication of innovations across social systems (Rogers, 2003). The diffusion process describes a type of communication in which ideas are shared across members of a community. The four key components of the diffusion of innovations theory include: 1) an idea, 2) a channel of communication, 3) time to implement innovations, and 4) a social system in which adoption takes place (Lionberger and Gwin, 1991; Rogers, 2003). In its constitution, the diffusion of innovation paradigm highlights the role that social networks play in facilitating the spread of new ideas through social contacts, a key pillar of the diffusion of innovation construct.

In its core framework, the diffusion of innovations theory provides key channels that underly the spread of innovations. The spread of innovations and their adoption occurs via social contacts and through a variety of actors (Rogers, 2003). Information sharing evolves through a process of divergence and convergence as the various actors receive and share these new ideas. The permeation of a new technology is not simply a linear process in which an extension agent directly communicates the innovation to a farmer and the farmer immediately adopts the innovation. Instead, the farmer may also learn of other innovations from a neighbour or ask for feedback from another farmer or another extension agent. In sum, the diffusion of innovation process entails an irregular communication process in which message exchange concerning novel technologies creates interest in participants in the sharing of information about these new innovations. As such, extension services that understand how this process occurs within a community could be well positioned to disseminate information about new agricultural technologies and practices.

\section{Evolution of Extension Services in Kenya}

The strategy of improving the rural agricultural sector has been a major concern not only for the national government of Kenya but also for the county government of Kakamega. Agriculture contributes to the overall economy of the country and helps combat poverty, food insecurity, and agricultural productivity. The dissemination of hybrid maize technologies in the late 1960s and early 1970s flourished due to the contribution of agricultural extension activities conducted across many parts of Kenya (Gautam, 2000).

To further enhance agricultural development in the early 1980s, the government of Kenya introduced a novel extension program, the Training and Visit (T\&V) 
program, with the goal of improving the timely delivery of information and skills training to local farmers. At that time, most national governments in developing countries viewed the delivery of information as a key strategy for improving crop yields (Anderson \& Feder, 2004). As a dominant traditional extension approach, the T\&V model focused on in-person visits with a training message that was standardized across all farms. At its inception, the program was considered an innovation in the management and organization of agricultural extension personnel. From 1982 to 1990, the T\&V model was considered a successful innovation in agricultural extension(Bindlish and Evenson, 1997). Extension agents worked with farmers through farm visits and addressed farmer concerns which were primarily about crop husbandry. However, during the 1990s, the T\&V model became expensive and unsustainable. Delivery of information and training to farmers was irregular and the standardized formatting of the messages often resulted in advice that was irrelevant to the particular farmers' needs (Howell, 1982). Overall, there was a decline in the effectiveness of the extension system due to a lack of adequate tailoring of agricultural messaging to the specific and expanding needs of individual farmers. In his assessment of the T\&V model, Howell (1982) concluded that this model provided farmers with irrelevant information, emphasizing quantitative targets over the quality of the information, and did not provide the level of expertise that farmers needed. Additionally, farm visits by extension agents during the implementation of the T\&V model often occurred to already successful farmers who would otherwise not need advice (Howell, 1982). In hindsight, the $T \& V$ program is generally characterized as one of the more haphazard and ineffective extension models, in part because it did not consider the role of farms and farmer characteristics and their influence on the adoption of new technologies.

Criticism of the $\mathrm{T} \& \mathrm{~V}$ program in the delivery of extension services prompted a global movement to reform national agricultural extension systems. Kenya was one of those countries that attempted to reform the extension system (Howell, 1982). Other developing countries also started to implement institutional and operational reforms designed to refine agricultural extension delivery and make it more suitable to the specific needs of the farmers. These reforms were hampered by poor management of the agricultural sector due to both the financial crises associated with reduced government funding and a legitimation crisis resulting from a lack of farmer confidence in extension (Davis, 2008; Vanclay and Lawrence, 1994). These obstacles necessitated a change in the delivery of agricultural extension services, leaving a theoretical void. Similarly in Kenya, agricultural extension reform became a controversial issue; where, in spite of the proposed reforms the extension system remains largely top-down and resistant to reform (Gautam, 2000; Muyanga and Jayne, 2008).

\section{The Need for New Agricultural Extension Models}

In spite of past failures in sub-Saharan Africa, agricultural extension, as a resource, still has a huge potential to contribute to the dissemination and adoption of agricultural practices in many sub-Saharan countries (Taye, 2013). Farmers continue to rely on the agricultural extension system in the delivery and adoption of a wide range of crop practices and technologies critical in increasing yields and incomes (Anang et al., 2020). Research has also shown that in areas where agricultural extension education and training have been successful, extension as a channel of innovation delivery has resulted in the improvement of agricultural productivity among smallholder farmers (Doss et al., 2003; Suvedi et al., 2017). Therefore, it is necessary to continue exploring agricultural delivery mechanisms likely to work in response to context-based agricultural challenges and local dynamics. The literature suggests that there is no standardized model that can be implemented anywhere (Davis, 2008).

Delivery of agricultural extension services has transitioned from the traditional emphasis on technology transfer and farm management information to addressing topics such as marketing, environmental sustainability, pest diagnostics, and risk management (Norton and Alwang, 2020). However, this transition has not fully occurred in developing country agriculture - it is however moving at a slow pace.

\section{Extant Extension Models in Developing Countries}

Three primary models are dominant in the delivery of extension services in agricultural communities in developing countries (Anandajayasekeram, 2008). These models vary across the various typologies of farmer service needs, scale of production, and their previous experience with extension. Model 1 features the offer of 
free public extension services, mostly to smallholder farmers growing staple foods and minor cash crops across various agroecological zones. In this model, farmers receive basic inputs such as seeds, fertilizer, and crop planting information from public extension services at no charge. Comparatively, in Model 2, farmers costshare the expense associated with extension services they receive either from public or private extension service providers. The effectiveness of this model is measured by farmers' willingness and ability to bear a share of the service cost (Anandajayasekeram, 2008). However, effective implementation of this service delivery model can run into potential problems if farmers are pressured into investing in technologies that are unproven. On the other hand, a major benefit of this model is farmer commitment to new practices, often demonstrated by a commitment to bear some of the costs. The limitations of this model include the difficulty of implementation due to the broad diversity of farmers' needs. Finally, Model 3 involves practitioners that practice fully commercialized agriculture and comprise of the private sector, private companies and cooperatives, and quasi-public firms growing commodities such as tea, coffee, and sugar (GOK, 2014). The scale of production permits large-scale agricultural producers to apply the latter model common among large-scale agricultural producers whose goal is to maximize their profit margin through the application of efficient production practices. Under the third extension model, the producer often deals with private sector service provider entities engaged in the production and distribution of seeds, fertilizers, and pesticides. This model is convenient for large scale producers with multiple financing sources that allows them to access the technologies and services that are primarily provided by private sector service providers (Mwangi and Kariuki, 2015). The success of the three extension models depends on the skill of extension educators and agents engaged in the specialized dissemination of agricultural knowledge and training effectively tailored to the needs of varied farming systems. The actors across the models are both private and public organizations who provide a broad range of assistance - such as the delivery of services and other innovations, agricultural marketing, or insurance services.

\section{METHODOLOGY}

This study applied a quantitative research approach to investigate its stated objective. In addressing the views of smallholder farmers towards agricultural extension practices, the first author orally administered a survey questionnaire among farmers regarding their opinions towards agricultural extension services. A variety of the survey questions focused on farmer views about ways of improving agricultural extension services. A total of seventy-eight (78) participants from across seven (7) out of the twelve (12) sub-counties in Kakamega County responded to the survey. Prior to its administration, the researcher contacted personnel from the Ministry of Agriculture, Fisheries, Livestock and Cooperatives for information about the general overview of agricultural extension services in Kakamega County.

A logistic regression model was used to investigate the farm and farmer traits likely to influence agricultural technology adoption. As a leading channel of diffusing agricultural innovations to farmers, particularly resource-limited smallholder farmers, public agricultural extension remains the main source of information and resources.

\section{Study Area}

The study was conducted in Kakamega County, located in western Kenya. Field data were collected from seven sub-counties (Table 1). The surveyed smallholder farmers practiced mixed farming - growing crops including cereals and other horticultural crops, and raising animals. Rainfed agriculture accounts for 95 percent of farmed land in sub-Saharan Africa. In Kakamega County, maize is a staple crop that most rural farmers grow in addition to other crops, when space permits (GOK, 2014). Several other horticultural products along with the maize crop are grown variably in the area. The agricultural production needs of the smallholder farmers in the area can be characterized as homogeneous: primarily including seeds, fertilizers, tractors, and other production implements. Notably, a common characteristic of the farmers in the region was the low uptake of new and yield-increasing agricultural practices and technologies.

Table 1 shows the sub-counties of the study, including the number of households surveyed per administrative region. Variability in the sub-county population guided the number of households that were surveyed. For example, compared to the other sub-counties, the population size of Navakholo Sub-county was larger 
than the other sub-counties that participated in the study.

Table 1. Smallholder households surveyed by Sub-county.

\begin{tabular}{lcc}
\hline Subcounty & Households & $\%$ \\
\hline Matungu & 08 & 10.1 \\
Navakholo & 21 & 26.6 \\
Lurambi & 11 & 13.9 \\
Ikolomani & 11 & 13.9 \\
Malava & 09 & 11.4 \\
Butere & 10 & 12.7 \\
Mumias East & 08 & 10.1 \\
\hline Total & 78 & 100 \\
\hline
\end{tabular}

\section{Study Participants and Sampling Protocol}

The selection of research participants followed a multistage random sampling approach. In the first stage of the site selection, seven out of the twelve sub-counties of Kakamega County, were deemed befitting the smallholder farmers in the study area. Sub-county selection was based on the size of the farms (smallholdings) and the type of crops grown. Maize and beans were the predominant agricultural products grown in the selected sub-counties. The five counties excluded from the study were characterized by the production of sugarcane, which typically required relatively larger land sizes.

The second stage involved a random selection of households to be included in the survey. The objective was to identify a representative sample of households meeting the designated profile of the smallholder farmers of interest. The target smallholder farmers were generally defined as those holding land sizes of less than 10 acres, practicing mixed agriculture, and producing mainly for household consumption. In aggregate, these farmers had a limited input budget and irregular access to local extension services. Their economic success was a result of the type of farming system they practiced, which ranked them unfavorably with their larger scale counterparts.

At the household level, an average of ten households were randomly selected from each sub-county for data collection. The data was obtained collected from a total of 78 smallholder households with 10 acres of farmland or less from across seven of the twelve sub-counties. The survey information collected pertained to farmer views towards extension, farm and farmer characteristics, cropping practices, overall agricultural production, and farmer perspectives of current agricultural challenges. The data that were collected covered two cropping seasons, the long-rain season (February to July) and the short-rains season (October to December). Farmers planted maize and beans during the long-rains, but only planed maize during the short rains.

\section{Data Analysis}

Data were collected using a questionnaire, focusing on farmer demographic characteristics, farmer perceptions of agricultural technologies and practices they applied in their own farms. To evaluate survey data, the research team first reviewed the raw data from the questionnaire responses obtained from the respondents to identify their demographics, their perceptions towards agricultural technologies, and the agricultural practices they applied in their own farms. After collecting and cleaning the raw survey data, we analyzed the data in order to answer the research questions with the view of obtaining an in-depth understanding of farmer subjective views. The raw data collected represented the two planting seasons practiced by farmers in the county. Some qualitative data was also obtained from the openended survey questions of farmer practices. Overall, the data featured existing technology challenges and local beliefs influencing farmer perceptions of agricultural practices.

Data was analysed using descriptive statistics and a binary logistic regression model. The quantitative data analysis was conducted using a binary logistic regression model. The explanatory variables in the regression equations captured socio-economic variables pertaining farmers' agricultural experience. The socioeconomic variables included gender, farm size, marital status, distance to input suppliers and farmer education level.

\section{Quantitative approach}

This study utilized a logistic regression model to estimate agricultural technology adoption by regressing technology adoption against a series of variables assumed to influence adoption. The dependent variable in the estimated equation is dichotomous and equals 1 if the $i$ th household head used an agricultural technology and 0 if not. Ordinary least squares (OLS) estimation is not appropriate for this estimation due to the dichotomous dependent variable. The logistic regression is used to ascertain the probability of an outcome 
captured in binary format. The socio-economic explanatory variables in this equation are widely applied in the literature - gender of the farmer, marital status, farmer education level, current farm size, and distance to local input supplier. These variables were chosen due to their common use in the adoption literature as predictors of technology adoption (Nyanga, 2012; Ochenje et al., 2016; Suvedi et al., 2017). In this study, fertilizer, an input commonly used by farmers, serves as a proxy for technology. The dependent variable is binary, taking a value of 1 for adoption and 0 for non-adoption. The selection of equation variables represents the farm and farmer characteristics of the farmers in the sample. The logistic regression applied in this estimation is specified as follows:

$\operatorname{Prob}\left(Y_{i}=1\right)=P_{i}=F\left(Z_{i}\right)=F\left(\propto+\sum\left(\beta_{i} X_{i}\right)=\frac{1}{1+e^{-Z_{i}}}\right.$

where $P_{i}$ represents the probability that a farmer participates in adopting a new practice or technology or not; $X_{i}$ represents explanatory variables (presumed predictor variables of technology adoption). The $\beta$ and $\alpha$ are the parameter estimates.

$\operatorname{Prob}\left(Y_{i}=0\right)=1-\operatorname{Prob}\left(Y_{i}=1\right)=\left(1-P_{i}\right)=\frac{1}{1+e^{Z_{i}}}$

From equation 1 and 2, we obtain

$\frac{\operatorname{Prob}\left(P_{i}=1\right)}{\operatorname{Prob}\left(P_{i}=0\right)}=\frac{P_{i}}{1-P_{i}}=e^{Z_{i}}$

In equation (3), $P_{i}$ is the probability that $Y_{i}$ takes the value 1 and $1-P_{i}$ is the probability that $Y_{i}$ takes the value 0 , and $e$ is the exponential constant.

Taking the natural log of both sides of equation (3), we get;

$Z_{i}=\ln \left(\frac{P_{i}}{1-P_{I}}\right)=\beta_{0}+\beta_{1} X_{1 i}+\beta_{2} X_{2 i}+\cdots+\beta_{k} X_{k i}+u_{i}$.

$Z_{t}$ is the dependent variable (fertilizer use) and $\beta_{0}$ to $\beta_{k}$ are the estimated parameters. The $X_{1 t} \ldots \ldots . X_{k t}$ are the independent variables in the equation that represent the factors that influence the adoption of agricultural practices. Suvedi et al. (2017) and Nyanga (2012) use a binary logistic model to estimate factors that influence the adoption of technology. In themselves, these explanatory factors are assumed to capture farmers' adoption decisions. The regressed variables (Table 2) include the household head's gender, marital status, education level, size of farm and the distance to fertilizer suppliers.

Table 2. Measured socio-economic variables.

\begin{tabular}{ll}
\hline Variable & Variable Measurement \\
\hline Gender & Male or female \\
\hline Marital status & Married or single \\
\hline Education level & Years of formal education \\
\hline Farm size & Farm size in acres \\
\hline & \\
\hline Distance to input suppliers & Distance in kilometers \\
\hline
\end{tabular}

\section{RESULTS}

This study sought to investigate the key factors that influenced agricultural technology adoption among smallholder farmers in Kakamega County, Kenya. To accomplish this objective, two primary research questions guided the study including, (RQ1): what are local farmer views of extension and the agricultural techniques it encourages among local farmers? and, (RQ2): what are the potential farm and farmer characteristics that influence technology adoption among smallholder farmers? To answer research question one (RQ1) regarding local farmers' views of extension and the agricultural techniques by farmers, respondents were asked to state their perceptions of agricultural extension services and potential ways of improving them (Table 3), and the skills they had received from extension agents on the topics of soil health (Table 4). Research question two (RQ2) on farm and farmer characteristics was investigated through a logistic regression equation whose results are presented in Table 5.

The first research question (RQ1) explored the farmers' perception of agricultural extension and the techniques promoted among farmers. As illustrated in Table 3, farmers chose the no response/opinion (55\%) most often, reflecting the reality that most of these farmers had limited or no interaction with agricultural extension on which to base their opinions. Comparatively, of those farmers who reported interacting with agricultural extension, 14\% suggested that increased training of extension agents was needed. Similarly, almost $13 \%$ of farmers indicated having more extension agents available would be desirable to increase farmer training. Direct farmer contact (9\%), cost sharing (3.8\%), and adequate government support $(2.6 \%)$ were also mentioned by the farmers as necessary in improving 
agricultural productivity. This insinuated a high demand for public agricultural extension education services among these resource-poor farmers. However, the farmer suggested that public agricultural extension was an unreliable source of providing necessary agricultural technology required in their farms.

Table 3. Responses to farmers perceptions of ways to improve agricultural extension services.

\begin{tabular}{lcc}
\hline Type of Response & Frequency & $\%$ \\
\hline No response/opinion & 43 & 55.1 \\
Increasing training frequency & 11 & 14.1 \\
Hire more extension agents & 10 & 12.8 \\
Direct Farmer contact & 07 & 9.00 \\
Co-share visit costs & 03 & 3.80 \\
Adequate gov't support & 02 & 2.60 \\
Missing & 02 & 2.60 \\
\hline Total & 78 & 100 \\
\hline
\end{tabular}

Table 4. Soil protection practices.

\begin{tabular}{lcc}
\hline Practices & Frequency & $\%$ \\
\hline Terracing & 37 & 26.4 \\
Applying manure & 31 & 22.1 \\
Creating borders & 27 & 19.3 \\
Crop rotation & 14 & 10.0 \\
Mulching & 09 & 6.40 \\
Using cover crops & 07 & 5.00 \\
Agroforestry & 05 & 3.60 \\
Applying aglime & 04 & 2.90 \\
Intercropping & 03 & 2.10 \\
Push-pull technology & 02 & 1.40 \\
Application of fertilizer & 01 & 0.70 \\
\hline
\end{tabular}

To further investigate farmers' perceptions of extension services (RQ1), participants were asked to discuss their soil protection practices. Soil advisory services include advice on techniques and technologies shared by extension agents, therefore providing an indirect means of assessing farmers' access to and perception of extension services. Table 4 reveals that soil health was essential in both the quality and quantity of agricultural output that a farmer obtained from the farm. Protecting the soil was an important step in improving agricultural output and farmers' implementation of extension advice. Farmers reported that soil protection was achieved by making terraces (26.4\%), applying manure $(22.1 \%)$ and creating borders in the farms (19.3\%). The skillintensive practices promoted by extension agents were least applied by farmers, i.e. applying lime (2.9\%), and intercropping $(2.1 \%)$, push-pull technologies $(1.4 \%)$, and appropriate application of fertilizer (0.7\%). Compared to the education and training activities that agricultural extension workers provided, integrated pest, weed, and soil management practices and fertilizer use are common inputs and practices promoted by local extension services. Push-pull technology, a novel conservation practice that is highly promoted among smallholder mixed cropping systems, and fertilizer use were reported to be applied minimally according to farmer views. The second research question (RQ2) explored the potential farm and farmer characteristics that influenced technology adoption among smallholder farmers. The farmer responses suggested that public agricultural extension was an unreliable source of providing necessary agricultural information apply in their farms. Table 5 presents the estimates of the logistic regression model where the response variable is the adoption of fertilizer, an indicator of technology adoption. The predictor variables were selected to capture farm and farmer characteristics and they include gender, marital status, education level, farm size, and distance to fertilizer sellers. These results indicate that the farm size positively predicted the adoption of a new technology by the households. The positive relationship between the adoption of a new agricultural practice and 
farm size explains an important dynamic of farmer rationality in technology choice. While this result does not fully capture the steps leading to the adoption of any new practice or technology, it provides evidence that the size of the farm is a critical variable in the agricultural technology adoption continuum. In the binary logistic model, the dependent variable, represented by fertilizer (analogous to technology), implies that increasing the farm size raises the probability of farmers' inclination to adopt the technology.

The positive coefficient of the farm size variable can be interpreted to suggest that changing the farm size influences the probability of the likelihood of farmers adopting an agricultural technology.

Table 5. Logistic regression model of factors determining the adoption of technology.

\begin{tabular}{lcccccccc}
\hline Variable & $\beta$ & S. E. & Wald & df & Sig. & $\operatorname{Exp}(\beta)$ & \multicolumn{2}{c}{ 95\% C.I. for Exp $(\beta)$} \\
\cline { 7 - 9 } & & & & & & & Lower & Upper \\
\hline Gender & 1.704 & 1.292 & 1.739 & 1 & 0.187 & 5.498 & 0.437 & 69.236 \\
Marital status & 0.206 & 1.156 & 0.032 & 1 & 0.859 & 1.229 & 0.128 & 11.836 \\
Education level & 0.305 & 0.415 & 0.539 & 1 & 0.463 & 1.357 & 0.601 & 03.062 \\
Farm size & 0.211 & 0.104 & 4.135 & 1 & $0.042^{*}$ & 1.235 & 1.008 & 01.513 \\
Distance to input suppliers & -0.900 & 1.013 & 0.790 & 1 & 0.374 & 0.407 & 0.056 & 02.958 \\
Constant & -6.416 & 4.070 & 2.486 & 1 & 0.115 & 0.002 & & \\
\hline
\end{tabular}

* significant at $95 \%$ level

Public and private agricultural extension service providers are an important channel of sharing information, training, and inputs with farmers. Extension educators share with farmers essential farming inputs (such as fertilizers, seeds, or relevant farming tools) and agricultural information for their farms during scheduled farm visits or when sought out for advice. Extension providers' understanding and knowledge of specific farm and farmer characteristics enables them to successfully tailor information and training to the specific farm or farmer needs.

This exploratory logistic model captured the uncertainty farmers face when making a technology adoption decision. It may be concluded from the study that larger scale farmers are more likely to accept risk or deal with risk uncertainty differently than their small-scale counterparts. This finding demonstrates that farm size is an important factor that farmers consider when making decisions on new choices of technologies. Farmers with smaller landholdings would need to receive additional training or financial support before trying a new technology or practice.

\section{CONCLUSION}

This paper aimed at identifying smallholder farmers' perceptions of agricultural extension services in the adoption of technologies. Further, the study sought to identify the farm and farmer characteristics that influenced agricultural technology use among the smallholder farmers in Kakamega County, Kenya. The farmers expressed interest in public agricultural extension but did not sufficiently gain from those services due to poor governance failures in their delivery. In assessing the farm and farmer characteristics influencing adoption, farm size was a positive predictor of agricultural technology adoption among farmers in the study area. The logistic model results suggested an important link between farm size and farmer technology adoption behavior.

In answering the question of farmer perceptions of agricultural extension, the surveyed farmers identified the limited role of agricultural extension services. This view supports the low ranking of the application of fertilizers and the use of push-pull technologies by farmers. Despite these practices' potential contribution to soil and crop health, farmers did not find them worth applying on their farms. The absence of a functional extension advisory framework is apparently a major limiting factor in farmer access to information and training. As a result, limited access to extension potentially hinders improvement of agricultural productivity in the study area.

In conclusion, the attitudes and perception of farmers towards agricultural extension presented in this exploratory study can only be appropriated for Kakamega County. A comparison of farmer attitudes could be beneficial for not only enhancing intervention and improving extension services, but also in 
customizing agricultural extension delivery in rural farm communities similar to those of Kakamega County, Kenya.

\section{IMPLICATIONS AND RECOMMENDATIONS}

This exploratory study investigated smallholder farmers' perceptions of agricultural extension and the farm and farmer characteristics likely to influence the adoption decisions of agricultural technologies. Survey data identifying farmer perceptions and farm and farmer characteristics was collected from 78 smallholder farmers of Kakamega County, Kenya. Descriptive survey data was analyzed to compliment a binary logistic model that estimated variables presumed to influence the adoption of fertilizer use among farmers.

In answering RQ1 (perceptions towards agricultural extension) and the factors that influence the adoption of new technologies, this study makes an important contribution in the discussion of ways that farmers with varying land sizes perceive new agricultural technologies. These findings support the consideration of farm size as an important variable in technology adoption. However, before generalizing such a recommendation across smallholder farmers in Kenya, similar research needs to be conducted in other areas.

In prior literature on the stochastic structure, farm size and technology adoption in developing countries has pointed to the variability of farm size in influencing farmer's appetite for, and the perception of risk associated with adopting new technologies (Just \& Zilberman, 1983). However, that study focused on the development of a framework for econometric estimation of production using a comparison between old and new technologies while not accounting for other variables. A similar study explored the farm size-productivity relationship in Kenya, but the study did not consider other variables influencing adoption (Muyanga \& Jayne, 2019).

The current study findings broaden the understanding of technology adoption by combining farmer perceptions of agricultural extension, and socio- economic variables, to conclude that farm size should be a critical consideration in adoption. The study findings identify the size of the farm as integral in influencing farmer technology adoption. The identification of farm size as a predicting variable in adoption suggests that extension methods should consider variability in farm size in the design of agricultural extension programs. Extension programming should recognize pertinent context-based characteristics in service delivery.

The delivery of new agricultural information, services, and products to farmers requires a better understanding of farm and farmer characteristics, including their openness to agricultural extension services. Historically, relevant literature in agricultural extension and adoption of agricultural practices has focused on socioeconomic variables as important determinants in the adoption of agricultural practices (Nyanga, 2012). From a practical standpoint, these variables can be important in influencing the diffusion or adoption of new agricultural practices, but a holistic consideration of other factors is critical and must be explored as a starting point of understanding the root cause of stagnation in technology adoption among Kenyan farmers. This study sought to extend the awareness of other key variables that influence technology adoption including the socio-demographic characteristics of the farmers, as well as their farm characteristics.

Regarding farmer views toward agricultural extension, the descriptive statistics suggested that farmers view agricultural extension as an important resource for the diffusion of agricultural information and training for rural farming activities. However, farmer views from the survey suggest that the sharing of agricultural knowledge must be accompanied by effective and welltrained extension personnel who direct their training specifically to the individualized characteristics of each farm. Farmers also indicated that more agricultural extension agents were needed to serve the large number of smallholder farming households across western Kenya, and to help in the dissemination of new technologies. Findings from this exploratory study are important in understanding rural communities and in the promotion of agricultural innovations that can potentially improve rural farming communities. The current findings provide an informed understanding of the role of extension in supporting rural smallholder farmers through extension programming tailored to the more risk averse smallholder farmers, who are a majority in the agricultural production of developing countries.

\section{REFERENCES}

Adolwa, I. S., S. Schwarze, B. Waswa and A. Buerkert. 2017. Understanding system innovation adoption: A comparative analysis of integrated 
soil fertility management uptake in Tamale (Ghana) and Kakamega (Kenya). Renewable Agriculture and Food Systems, 34: 313-25.

Ali-Olub, A. M., N. Kathuri and T. E. Wesonga. 2011. Effective extension methods for increased food production in Kakamega District. Journal of Agricultural Extension and Rural Development, 3: 95-101.

Anandajayasekeram, P. 2008. Concepts and practices in agricultural extension in developing countries: A source book ILRI (aka ILCA and ILRAD).

Anang, B. T., S. Bäckman and T. Sipiläinen. 2020. Adoption and income effects of agricultural extension in northern Ghana. Scientific African, 7: e00219.

Aura, S. 2016. Determinants of the adoption of integrated soil fertility management technologies in mbale division, Kenya. African Journal of Food, Agriculture, Nutrition and Development, 16: 10701-14.

Bindlish, V. and R. E. Evenson. 1997. The Impact of T\&V Extension in Africa: The Experience of Kenya and Burkina Faso. The World Bank Research Observer, 12: 183-201.

Davis, K. 2008. Extension in sub-Saharan Africa: Overview and assessment of past and current models and future prospects. Journal of International Agricultural and Extension Education, 15: 15-28.

Doss, C. R., W. Mwangi, H. Verkuijl and H. De Groote. 2003. Adoption of maize and wheat technologies in eastern Africa: a synthesis of the findings of 22 case studies CIMMYT.

Gautam, M. 2000. Agricultural Extension. The World Bank.

GOK. 2014. Household Baseline Survey Report: Kakamega County.

Howell, J. 1982. Managing agricultural extension: The T and $\mathrm{V}$ system in practice. Agricultural Administration, 11: 273-84.

Lionberger, H. F. and P. H. Gwin. 1991. Technology transfer: from researchers to users a textbook of successful research extension strategies used to develop agriculture University of Missouri, University Extension.

Mutua, F., S. Arimi, W. Ogara, C. Dewey and E. Schelling. 2010. Farmer perceptions on indigenous pig farming in Kakamega district, Western Kenya. Nordic Journal of African Studies, 19: 15-15.

Muyanga, M. and T. S. Jayne. 2008. Private Agricultural Extension System in Kenya: Practice and Policy Lessons. The Journal of Agricultural Education and Extension, 14: 111-24.

Mwangi, M. and S. Kariuki. 2015. Factors determining adoption of new agricultural technology by smallholder farmers in developing countries. Journal of Economics and sustainable development, 6 .

Mwaura, G. G., M. N. Kiboi, E. K. Bett, J. N. Mugwe, A. Muriuki, G. Nicolay and F. K. Ngetich. 2021. Adoption Intensity of Selected Organic-Based Soil Fertility Management Technologies in the Central Highlands of Kenya. Frontiers in Sustainable Food Systems, 4.

Norton, G. W. and J. Alwang. 2020. Changes in Agricultural Extension and Implications for Farmer Adoption of New Practices. Applied Economic Perspectives and Policy, 42: 8-20.

Nyanga, P. H. 2012. Factors Influencing Adoption and Area under Conservation Agriculture: A Mixed Methods Approach. Sustainable Agriculture Research, 1: 27.

Ochenje, I., C. Ritho, P. Guthiga and O. Mbatia. 2016. Assessment of farmers' perception to the effects of climate change on water resources at farm level: the case of Kakamega county, Kenya 2016 Fifth International Conference, September 2326, 2016, Addis Ababa, Ethiopia 249339, African Association of Agricultural Economists (AAAE).

Odulaja, A. and F. G. Kiros. 1996. Modelling agricultural production of small-scale farmers in sub-Saharan Africa: A case study in western Kenya. Agricultural Economics, 14: 85-91.

Ogada, M. J., G. Mwabu and D. Muchai. 2014. Farm technology adoption in Kenya: a simultaneous estimation of inorganic fertilizer and improved maize variety adoption decisions. Agricultural and Food Economics, 2.

Rogers, E. M. 2003. Diffusion of Innovations. In Diffusion of Innovations Free Press.

Suvedi, M., R. Ghimire and M. Kaplowitz. 2017. Farmers' participation in extension programs and technology adoption in rural Nepal: a logistic regression analysis. The Journal of Agricultural Education and Extension, 23: 351-71. 
Taye, H. 2013. Evaluating the impact of agricultural extension programmes in sub-Saharan Africa: Challenges and prospects. African Evaluation Journal, 1.

Tittonell, P., B. Vanlauwe, P. A. Leffelaar, E. C. Rowe and K. E. Giller. 2005. Exploring diversity in soil fertility management of smallholder farms in western Kenya. Agriculture, ecosystems \& environment, 110: 149-65.

Vanclay, F. and G. Lawrence. 1994. Farmer rationality and the adoption of environmentally sound practices; A critique of the assumptions of traditional agricultural extension. European Journal of Agricultural Education and Extension, 1:59-90. 